\title{
PENGARUH TRAIT KEPRIBADIAN BIG FIVE DAN SELF- CONTROL TERHADAP RISK TAKING BEHAVIOR PADA PEKERJA KONSTRUKSI
}

\author{
Arya Ersyaf Gucciano \\ arya.gucciano@gmail.com \\ Anggota HIMPSI Provinsi Banten
}

\author{
Nia Tresniasari \\ tresniasari.nia@gmail.com \\ Fakultas Psikologi UIN Syarif \\ Hidayatullah Jakarta
}

\begin{abstract}
The Construction sector has a higher risk of accidental employment compared to other labor sectors in Indonesia. Therefore, it is important for construction workers to have knowledge of the dangers and vulnerability that can occur. This study aims to determine the effect of trait big personality five and self-control against risk taking behavior in construction workers. Sample amounted to 213 construction workers taken by accidental sampling technique. Instruments used in this study there are three scales, namely scale DOSPERT (Domain Specific Risk Taking), scale of five inventory and scale of self-control scale. Test the validity of the measuring instrument using confirmatory factor analysis (CFA) technique. While the data analysis using multiple regression techniques. The results of this study indicate that there is a significant influence of the trait of big five personality and self-control on risk taking behavior in construction workers. The amount of influence of all independent variables on risk taking behavior is $40.4 \%$, while the rest is influenced by other variables outside this research. While the results of the analysis of the proportion of variance of each variable separately, found the largest contribution to risk taking behavior is neuroticism, agreeableness, openness to experience, conscientiousness of the big five personality trait, and self-control variables. This research will get better results when using a wider population, in order to obtain more diverse data and can compare with factors that have not been studied.
\end{abstract}

Keyword:big five personality, self-control, risk taking behavior

\begin{abstract}
Abstrak
Sektor Konstruksi memiliki risiko timbulnya kecelakaan kerja yang tinggi dibanding dengan sektor tenaga kerja lain di Indonesia. Oleh karena itu, penting sekali untuk para pekerja konstruksi memiliki pengetahuan tentang bahaya dan kecelekaan yang dapat terjadi. Penelitian ini bertujuan untuk mengetahui pengaruh trait kepribadian big five dan self-control terhadap risk taking behaviour pada pekerja konstruksi. Sampel berjumlah 213 pekerja konstruksi yang diambil dengan teknik accidental sampling. Instrumen yang digunakan dalam penelitian ini terdapat tiga skala, yaitu skala DOSPERT (Domain Specific Risk Taking), skala big five inventory dan skala self-control scale. Uji validitas alat ukur menggunakan teknik confirmatory factor analysis (CFA). Sedangkan analisis data menggunakan teknik multiple regression. Hasil penelitian ini menunjukkan bahwa ada pengaruh yang signifikan dari trait kepribadian big five dan self-control terhadap risk taking behaviour pada pekerja konstruksi. Besarnya pengaruh seluruh variabel independen terhadap risk taking behaviour adalah sebesar $40,4 \%$, sedangkan sisanya dipengaruhi oleh variabel lain di luar penelitian ini. Sementara hasil analisis proporsi varians masing-masing variabel secara terpisah, ditemukan sumbangan yang paling besar terhadap risk taking behaviour adalah neuroticism, agreeableness, openness to experience, conscientiousness dari trait kepribadian big five, dan variabel self-control. Penelitian ini akan mendapatkan hasil yang lebih baik apabila menggunakan populasi yang lebih luas, agar mendapatkan data yang lebih beragam dan dapat membandingkan dengan faktor yang belum bisa diteliti.
\end{abstract}

Katakunci:trait kepribadian big five, self-control, risk taking behavior

Diterima: 13 April 2017 Direvisi: 19 Mei 2017 Disetujui:25 Juni 2017 


\section{PENDAHULUAN}

Sektor konstruksi memiliki risiko kecelakaan kerja yang tinggi dibanding dengan sektor tenaga kerja lain di Indonesia. Sebagai contoh beberapa kasus kecelakaan kerja, kegagalan konstruksi dan kegagalan bangunan yang terjadi beberapa tahun terakhir antara lain, robohnya Jembatan Kutai Kertanegara di Kalimantan Timur (Rurit, 2011) yang terjadi pada saat pekerjaan pemeliharaan dilakukan, robohnya Tower crane di proyek pembangunan apartemen Green Lake View di Ciputat, Tangerang Selatan (Liputan 6, 2013), runtuhnya hanggar bandara udara Sultan Hasanudin (Sutrisno, 2015), tergulingnya Crane di proyek normalisasi sungai Ciliwung (Pratama, 2015), dan jatuhnya gondola di Intiland Tower Jakarta Utara (Purba, 2016).

Salah satu faktor yang memicu timbulnya kecelakaan kerja adalah minimnya pekerja konstruksi yang memiliki kualifikasi yang layak dan bersertifikasi resmi. Sekretaris Jenderal Kementerian Pekerjaan Umum dan Perumahan Rakyat (PUPR) Taufik Widjoyono menyatakan, dari 9 juta tenaga kerja konstruksi di Indonesia, sebanyak 109.000 tenaga ahli bersertifikasi, 387.000 orang tenaga terampil dan 478 orang disetarakan dapat bekerja di kawasan ASEAN. Hal ini menunjukkan bahwa pekerja konstruksi di Indonesia masih cukup minim pengalaman dalam pelaksanaan di lapangan.

Dikhawatirkan pekerja konstruksi tanpa sertifikasi dapat mengalami risiko kecelakaan kerja yang lebih tinggi dibanding pekerja yang telah memiliki sertifikasi. Seperti contoh saat penulis melakukan observasi ke berbagai proyek konstruksi MRT di wilayah Jakarta, penulis mendapati pekerja yang sedang beristirahat di area konstruksi tetapi alat keselamatannya tidak digunakan, saat alat berat selesai digunakan para pekerja hanya meninggalkan begitu saja tanpa diamankan. Hal ini dapat dijadikan acuan penelitian ini dikarenakan masih ada para pekerja yang tidak memenuhi aturan keselamatan dan kesehatan kerja sehingga perlu dilakukan penelitian untuk melihat faktor-faktor apa yang dapat mempengaruhi perilaku berisiko pada pekerja.

Keselamatan pekerja konstruksi ini digunakan untuk memberikan perlindungan dan himbauan, bukan hanya sebatas aturan biasa mengingat penggunaan alat berat yang memiliki resiko tinggi belum lagi kondisi lapangan yang penuh dengan benda berbahaya. Kecelakaan sering kali dialami, dampaknya juga tak sekedar luka lecet, melainkan cacat bahkan kematian (Adiska, 2015).

Kecelakaan terjadi karena perilaku para pekerja di lapangan yang secara tidak langsung dapat memunculkan perilaku risk-taking. Shimmin, Corbett \& McHugh, (1980) menyatakan bahwa risk taking dapat disebabkan oleh tindakan pekerja yang menolak untuk memakai helm pengaman, pelindung pakaian dan sabuk pengaman, berjalan di atas balok tinggi, bekerja pada tangga yang tidak aman, lubang parit yang berbahaya dan sebagainya.

Menurut Byrnes, Miller, \& Schafer, (1999) perilaku risk-taking adalah perilaku yang secara tidak langsung dapat memunculkan potensi timbulnya konsekuensi baik positif maupun negatif. Penelitian Hinze (2006) menunjukkan bahwa lebih dari $75 \%$ cedera dalam konstruksi disebabkan oleh tindakan pekerja yang tidak aman yang didapatkan dari hasil pelatihan yang buruk, kurangnya keterampilan 
untuk mengenali bahaya, sistem keamanan yang tidak memadai, dan perilaku yang mengakibatkan munculnya risiko.

Selain itu, menurut Perkins, (2002b) perilaku risk-taking memiliki pengaruh yang tidak hanya terjadi dalam aspek keselamatan saja, tetapi memiliki probabilitas konsekuensi negatif secara signifikan dalam aspek lain yaitu dalam aspek kesehatan, sosial, dan hukum. Para pekerja konstruksi dalam melakukan pekerjaannya selalu dihadapkan pada situasi yang dapat memunculkan perilaku risk-taking. Carter dan Smith (2006) menjelaskan bahwa perilaku risk-taking berasal dari ketidakmampuan pekerja dalam memahami dan menanggapi risiko secara memadai sehingga perlu adanya pemahaman tentang faktor psikologis yang mempengaruhi perilaku risk-taking.

Risk taking behaviour sendiri dipengaruhi juga oleh beberapa faktor-faktor, Menurut Gullone \& Moore (1996) faktor-faktor yang mempengaruhi tersebut yaitu belief tentang risiko, jenis kelamin, usia, kepribadian dan self-control. Salah satu faktor yang mempengaruhi perilaku risk-taking yaitu Self-control. Menurut para ahli dapat dikemukakan bahwa self-control membuat seseorang menahan suatu respon yang dianggap negatif dan mengarahkannya kepada respon lain yang lebih baik dalam segi self-discipline, deliberate/nonimpulsive, healthy habits, work ethic, dan reliability (Tangney, Baumeister, \& Boone, 2004). Individu dengan self-control yang tinggi akan berusaha menghindari perilaku risk taking tinggi dalam pengambilan keputusan.

Self-control dikatakan sebagai kemampuan manusia untuk menahan dan mengendalikan perilaku sosial yang tidak pantas (DeWall, Baumeister, Stillman, \& Gailliot, 2005). Hal ini diperkuat oleh hasil penelitian DeWall, Finkel, dan Denson (2011) yang menyatakan bahwa kegagalan self-control dapat memberikan kontribusi untuk tindakan yang paling agresif yang menyertakan kekerasan. Ketika agresi mendesak menjadi aktif, self-control dapat membantu seseorang mengabaikan keinginan untuk berperilaku agresif, dan akan membantu seseorang merespon sesuai dengan standar pribadi atau standar sosial yang dapat menekan perilaku agresif tersebut. Penjelasan lain juga menunjukkan bahwa individu yang memiliki sifat pengendalian diri yang rendah lebih mungkin untuk terlibat dalam perilaku criminal, dan menyimpang dibandingkan dengan mereka yang memiliki tingkat selfcontrol yang tinggi (McMullen, 1999).

Faktor lain yang mempengaruhi perilaku risk-taking yaitu kepribadian para pekerja. Salah satu teori tentang kepribadian mengenalkan bentuk dimensi kepribadian big five yaitu neuroticism, extraversion, openness to experience, agreeableness, dan conscientiousness (Gullone and Moore, 2000). Dalam penelitian lainnya ditemukan bahwa dimensi dari five factor personality ini mewakili cara yang penting, dimana setiap manusia memiliki cara pandang yang berbeda satu sama lain dalam memprediksi perilaku yang dilakukan saat ini dan apa yang akan terjadi di masa yang akan datang, khususnya perilaku yang dikategorikan sebagai perilaku berisiko. (McCrae \& John, 1992).

Perilaku risk-taking dijelaskan sebagai penggabungan dari beberapa trait kepribadian Big Five (Nicholson, Soane, Fenton-O'Creevy, \& Willman, 2005). Penelitian Zuckerman, Kuhlman, Thornquist, \& Kiers (1991) menyatakan pekerja yang memiliki kecenderungan risk-taking behaviour yang tinggi, memiliki impulse 
sensation seeking yang lebih tinggi dan lebih cepat beradaptasi dalam melakukan perilaku risk-taking daripada pekerja yang lain. Hal ini disebabkan karena pekerja cenderung meremehkan kemungkinan terjadinya kecelakaan atau karena merasakan stimulasi yang lebih dalam melakukan pekerjaan yang berisiko. Dengan demikian, dapat disimpulkan perilaku risk-taking memiliki hubungan yang negatif terhadap kemampuan kerja dan hubungan yang positif terhadap keselamatan kerja.

Berdasarkan uraian latar belakang diatas, timbul pertanyaan mengenai apakah trait kepribadian big five dan self-control memiliki pengaruh untuk mengurangi tingkat risk taking behaviour? Hal ini dirasa penting guna mengurangi tingkat kecelakaan kerja. Untuk itu, peneliti tertarik untuk melakukan penelitian mengenai "Pengaruh trait kepribadian big five dan self-control terhadap risk taking behavior pada pekerja konstruksi".

\section{METODE PENELITIAN}

Penelitian ini menggunakan pendekatan kuantitatif dengan analisis multiple regression. Populasi dalam penelitian ini adalah pekerja konstruksi MRT di wilayah Jakarta Selatan. Jumlah sampel pada penelitian ini berjumlah 213 orang. Pengambilan sampel pada penelitian ini menggunakan teknik non-probability sampling.

Alat ukur yang digunakan untuk mengukur risk taking behaviour disusun oleh peneliti sebanyak 25 item berdasarkan aspek yang dikemukakan oleh Weber, Blaitz \& Betz (2003) yang meliputi Ethical, Financial, Health \& Safety, Recreational dan Social yang berkaitan dengan risk taking behaviour. Kemudian instrumen yang digunakan untuk mengukur trait kepribadian big five dalam penelitian ini adalah modifikasi alat ukur yang dikembangkan oleh John \& Srivastva (1999) yang terdiri dari 44 item. Kemudian untuk mengukur self-control memodifikasi alat ukur BriefSelf-control Scale (BSCS) dari Tangney, Baumiester, \& Boone (2004) yang terdiri dari 13 item.

Dalam rangka menguji hipotesis penelitian, penulis menggunakan analisis regresi berganda. Dalam hal ini yang dijadikan DV (variabel yang dianalisis variannya) adalah risk taking behaviour, sedangkan yang dijadikan IV (prediktor) adalah neuroticism, extraversion. Openness to experience, agreeableness dan conscientiousness, self-control dan usia. berikut:

Adapun persamaan regresi berganda untuk penelitian ini adalah sebagai

$$
\begin{aligned}
& \mathbf{Y}^{\prime}=\mathbf{a}+\mathbf{b}_{1} \mathbf{X}_{1}+\mathbf{b}_{2} \mathbf{X}_{2}+\mathbf{b}_{3} \mathbf{X}_{3}+\mathbf{b}_{4} \mathbf{X}_{4}+\mathbf{b}_{5} \mathbf{X}_{5}+\mathbf{b}_{6} \mathbf{X}_{6}+\mathbf{b}_{7} \mathbf{X}_{7}+\mathbf{b}_{8} \mathbf{X}_{8}+\boldsymbol{e} \\
& \text { keterangan : } \\
& \mathrm{Y}^{\prime} \quad=\text { Nilai prediksi } \mathrm{Y} \text { (Intensi anti korupsi) } \\
& \mathrm{a} \quad=\text { intercept (konstan) } \\
& \mathrm{b} \quad=\text { koefisien regresi untuk masing-masing X } \\
& \mathrm{X}_{1} \quad=\text { Neuroticism } \\
& \mathrm{X}_{2} \quad=\text { Extraversion } \\
& \mathrm{X}_{3} \quad=\text { Openness to experience } \\
& \mathrm{X}_{4} \quad=\text { Agreeableness }
\end{aligned}
$$




$$
\begin{array}{ll}
\mathrm{X}_{5} & =\text { Conscientiousness } \\
\mathrm{X}_{6} & =\text { self-control } \\
\mathrm{X}_{7} & =\text { Usia } \\
e & =\text { residu }
\end{array}
$$

\section{HASIL PENELITIAN}

Pada tabel 1 dapat dilihat bahwa diperoleh $R$-square sebesar 0.404 atau sebesar $40.4 \%$ Artinya, proporsi varian dari risk taking behaviour yang dijelaskan oleh trait kepribadian big five (neuroticism, extraversion, openness to experience, agreeableness, conscientiousness), self-control dan usia adalah sebesar 40,4\%, sedangkan 59,6\% sisanya dipengaruhi oleh variabel lain di luar penelitian ini.

\section{Tabel 1}

$R$ square

\begin{tabular}{cccccc}
\hline Model & $\mathrm{R}$ & $R$ Square & Adjusted $R$ Square & Std. Error of the Estimate & \\
\hline & 1 & $.635^{\mathrm{a}}$ & .404 & .380 & 7.33459 \\
\hline
\end{tabular}

Langkah kedua peneliti menguji apakah seluruh independen memiliki pengaruh yang signifikan terhadap risk taking behaviour. Adapun hasil uji $\mathrm{F}$ dapat dilihat pada tabel 2 .

\section{Tabel 2}

Anova pengaruh seluruh IV terhadap DV

\begin{tabular}{ccccccc}
\hline & Model & Sum of Squares & $\mathrm{df}$ & Mean Square & $\mathrm{F}$ & Sig. \\
\hline 1 & Regression & 7389.528 & 8 & 923.691 & 17.170 & $.000^{\mathrm{a}}$ \\
& Residual & 10920.631 & 203 & 53.796 & & \\
& Total & 18310.158 & 144 & & & \\
\hline
\end{tabular}
a. Predictors: (Constant), neuroticism, extraversion, openness to experience, agreeableness, conscientic self-control, usia
b. Dependent Variable: risk taking behavior

Berdasarkan uji $\mathrm{F}$ pada tabel 2, dapat dilihat bahwa nilai $\mathrm{p}$ (Sig.) pada kolom paling kanan adalah $\mathrm{p}=0.000$ dengan nilai $\mathrm{p}<0.05$. Jadi, dengan demikian hipotesis mayor yang berbunyi "trait kepribadian big five, self-control dan usia memiliki pengaruh yang signifikan terhadap risk taking behaviour" diterima. Artinya, ada pengaruh yang signifikan trait kepribadian big five, self-control dan usia terhadap risk taking behaviour.

Langkah selanjutnya, peneliti melihat koefisien regresi dari masing-masing IV. Jika sig $<0,05$ maka koefisien regresi tersebut signifikan yang berarti variabel independen tersebut memiliki pengaruh yang signifikan terhadap risk taing behaviour. Adapun besarnya koefisien regresi dari masing-masing variabel independen terhadap kesejahteraan subjektif dapat dilihat pada tabel 3 . 
Tabel 3

Koefisien Regresi

\begin{tabular}{llccccc}
\hline \multicolumn{1}{c}{ Model } & \multicolumn{2}{c}{$\begin{array}{c}\text { Unstandardized } \\
\text { Coefficients }\end{array}$} & Standardized & & \\
& \multicolumn{1}{c}{ B } & Std. Error & Beta & Coefficients & $T$ & Sig. \\
\hline $1 \quad$ (Constant) & 84.131 & 7.804 & & 10.780 & .000 \\
& Neuroticism & .149 & .073 & .119 & 2.029 & $.044^{*}$ \\
& Extraversion & .095 & .069 & .081 & 1.371 & .172 \\
& Openness to experience & -.156 & .076 & -.149 & -2.042 & $.042^{*}$ \\
Agreeableness & -.284 & .081 & -.246 & -3.512 & $.001^{*}$ \\
& Conscientiousness & -.242 & .081 & -.187 & -3.000 & $.003^{*}$ \\
self-control & -.244 & .070 & -.218 & -3.492 & $.001^{*}$ \\
& Remaja & -.773 & 1.530 & -.030 & -.505 & .614 \\
& Dewasa akhir & .077 & 1.152 & .004 & .067 & .947 \\
\hline
\end{tabular}

a. Dependent Variable: Risk taking behaviour

Berdasarkan koefisien regresi pada tabel 3, maka persamaan regresinya sebagai berikut: (*signifikan)

Risk Taking Behavior $=84.131+0.149$ neuritucim $* 0.095$ extraversion 0.156 openness_to_experience* -0.284 agreeableness* -0.242 conscientiousness ${ }^{*}-0.244$ self_control* -0.773 remaja +0.077 dewasa-akhir.

Dari persamaan regresi tersebut, dapat diketahui bahwa terdapat lima varibel yang memiliki nilai koefisien regresi signifikan, yaitu; (1) neuroticism; (2) openness to experience; (3) agreeableness; (4) conscientiousness; (5) self-control.

\section{KESIMPULAN DAN SARAN}

\section{Kesimpulan}

Berdasarkan hasil dari analisa data dan pengujian hipotesis yang telah dilakukan dapat disimpulkan bahwa terdapat pengaruh seara keseluruhan yang positif antara trait kepribadian big five dan self-control terhadap risk taking behavior pada pekerja konstruksi. Artinya ada pengaruh yang signifikan dari masing masing independent variabel terhadap risk taking behavior pada pekerja konstruksi. Selain itu penelitian ini juga menjelaskan bahwa dimensi neuroticism, agreeableness, conscientiousness dari trait kepribadian big five mempunyai pengaruh signifikan dengan nilai positif, artinya semakin tinggi tingkat neuroticism, agreeableness dan conscientiousness seseorang maka semakin tinggi pula kecenderungan risk taking behavior individu. Hal ini sejalan dengan penelitian yang dikemukakan oleh Gullen and Moore, 2000 yaitu individu yang memiliki traitneuroticism, agreeableness dan conscientiousness tinggi memiliki risk taking behavior yang tinggi pula.Semakin tinggi skor individu dalam dimensi neuroticism, agreeableness dan conscientiousness maka individu tersebut mudah untuk beradaptasi dalam lingkungan dan memiliki kedisiplinan diri yang baik, akan tetapi rentan terhadap kecemasan dan gangguan stress saat bekerja. 


\section{Diskusi}

Berdasarkan hasil yang telah dijelaskan sebelumnya, diketahui bahwa berdasarkan hasil dari analisa data dan pengujian hipotesis yang telah dilakukan dapat disimpulkan bahwa terdapat pengaruh seara keseluruhan yang positif antara trait kepribadian big five dan self-control terhadap risk taking behavior pada pekerja konstruksi. Artinya ada pengaruh yang signifikan dari masing masing independent variabel terhadap risk taking behavior pada pekerja konstruksi. Selain itu penelitian ini juga menjelaskan bahwa dimensi neuroticism, agreeableness, conscientiousness dari trait kepribadian big five mempunyai pengaruh signifikan dengan nilai positif, artinya semakin tinggi tingkat neuroticism, agreeableness dan conscientiousness seseorang maka semakin tinggi pula kecenderungan risk taking behavior individu. Hal ini sejalan dengan penelitian yang dikemukakan oleh Gullen and Moore, 2000 yaitu individu yang memiliki traitneuroticism, agreeableness dan conscientiousness tinggi memiliki risk taking behavior yang tinggi pula.Semakin tinggi skor individu dalam dimensi neuroticism, agreeableness dan conscientiousness maka individu tersebut mudah untuk beradaptasi dalam lingkungan dan memiliki kedisiplinan diri yang baik, akan tetapi rentan terhadap kecemasan dan gangguan stress saat bekerja.

Pada penelitian ini ditemukan bahwa dimensi extraversion tidak signifikan terhadap risk taking behavior pada pekerja konstruksi, artinya tidak ada pengaruh dari extraversion terhadap risk taking behavior pada pekerja konstruksi. hal ini sesuai dengan penelitian sebelumnya dari McGhee et al (2012), yang membuktikan bahwa hasilnya berbanding terbalik dikarenakan sampel yang digunakan dalam penelitian adalah pekerja konstruksi, sedangkan sampel yang digunakan oleh peneliti tersebut adalah anak umur 11-12 tahun. Perbedaan sampel tersebut terletak pada sisi emosi yang berbeda antara pekerja dan anak, dimana pekerja memiliki emosi yang lebih stabil dibandingkan dengan anak

Selanjutnya dimensi openness to experience ditemukan signifikan terhadap risk taking behavior pada pekerja konstruksi dengan arah negative, artinya jika semakin tinggi tingkat openness to experience individu maka semakin rendah kecenderungan risk taking behavior. Peneliti menemukan beberapa literatur dari Anic (2007) yang mengatakan bahwa dimensi openness to experience berpengaruh terhadap risk taking behavior tetapi penelitian tersebut menggunakan sampel mahasiswa dan jenis kelamin sedangkan penelitian ini menggunakan sampel pekerja konstruksi dan hanya melakukan penelitian pada satu jenis kelamin saja.

Selanjutnya adalah variabel self-control. Dalam penelitian ini ditemukan bahwa self-control memiliki pengaruh yang signifikan terhadap risk taking behavior pada pekerja konstruksi dikarenakan dalam lingkungan konstruksi rentan terjadi kecelakaan yang dapat menimbulkan risiko cacat bahkan kematian. Jika self-control tinggi, individu akan berusaha menahan diri untuk melakukan perilaku yang berisiko tinggi tersebut sebaliknya jika self-control rendah individu cenderung lebih terlibat dalam perilaku yang berisiko tinggi tersebut.

\section{Saran}

Pada penelitian ini, penulis membagi saran menjadi dua, yaitu saran metodologis dan saran praktis.

\section{Saran Teoritis}


1. Disarankan bagi peneliti selanjutnya untuk meneliti variabel yang dapat meningkatkan self-control secara signifikan..

2. Untuk penelitian selanjutnya dapat diperkaya dengan membandingkan antara risk taking behavior pada kelompok laki-laki dengan risk taking behavior pada kelompok perempuan yang tentunya jenis kelamin memiliki banyak perbedaan satu sama lain.

3. Pada penelitian ini diketahui neuroticism berpengaruh positif terhadap risk taking behavior artinya individu dengan neuroticism tinggi cenderung tinggi perilaku risk taking behavior. Maka dalam penelitian lebih lanjut dapat disarankan meneliti faktor-faktor yang dapat membantu menurunkan risk taking behavior pada individu yang memiliki neuroticism tinggi.

\section{Saran Praktis}

1. Diharapkan kepada perusahaan untuk dapat memilih calon pekerja dengan tipe kepribadian openness to experience, agreeableness dan conscientiousness terutama individu dengan kepribadian agreeableness karena tipe kepribadian ini cenderung menurut pada aturan yang ditetapkan oleh atasan

2. Dalam meningkatkan tingkat risk taking behaviour dapat dimulai dari diri sendiri. Maka dapat disarankan kepada perusahaan untuk dapat menginisiasi pelatihan-pelatihan yang dapat meningkatkan self-control

\section{DAFTAR PUSTAKA}

Acocella, J. R., \& Calhoun, J. F. (1990). Psychology of adjustment human relationship (3thed). New York : McGraw-Hill.

Allport, G.W. (1961). Pattern and growth in personality. New York: Holt, Rinehart \& Winston

Anic, G. (2007). The association between risk taking and personality. theses of university of south florida

Averill. J.R. 1973. Personal Control Over Aversive Stimuli and its Relationship to Stress. Psychological Bulletin 286-303 University of Massachusetts.

Byrnes, James P.; Miller, David C.; Schafer, William D. (1999) Gender differences in risk taking: A meta-analysis. Psychological Bulletin, Vol 125(3), 367-383.

Carter, G and Smith, S D (2006) Safety hazard identification on construction projects. Journal of Construction Engineering and Management, ASCE, Vol. 132,(2), 197-205

Carver, C and Scheier, M F (1982) Control theory: A useful conceptual framework for personality-social, clinical, and health psychology. Psychological Bulletin 92(1): 111-35

Chaplin, J.P. (2006). Kamus Lengkap Psikologi. Edisi Ke-5. Terjemahan: Kartini Kartono. Jakarta: PT Raja Grafindo Persada.

DeWall, C. N., Baumeister, R. F., Stillman, T. F., \& Gailliot, M. T. (2005). Violence restrained: Effects of self-regulatory capacity and its depletion on aggressive behavior. Journal of Experimental Social Psychology 43(2007) 62-76

DeWall C.N, Finkel E.J, Denson T.F. (2011) self-control and aggression. Association for psychological science.;21(1):20-25 
Denny, S. (2017, 07 08). MRT butuh banyak tenaga kerja hingga 2019. Retrieved 07 08, 2017, http://bisnis.liputan6.com/read/3012286/mrt-butuh-banyaktenaga-kerja-hingga-2019

DiClemente, R. J., Hansen, W. B., \& Ponton, L. E. (1996). Adolescents at risk: A generation in jeopardy. In R.J. Di-Clemente, W. B. Hansen, \& L. E.. Ponton (Eds.), Handbook of adolescent health risk behavior (pp. 1 -4). New York: Plenum

Feist, Jess and Gregory J. Feist. 2006. Theories of Personality. Boston: McGrawHill Education.

Freeman, N. and Muraven, M. (2010). self-control depletion leads to risk taking: Journal of social psychological and personality science, 1(2), 175-181

Ghotnian, S., Tojari, F., Ganjoyi, F. A. (2013). Study of risk taking behavior as performance predictor: Journal of Social and behavioural sciences, 82, 351354

Gullone E, Moore S (2000). Adolescent risk-taking and the five-factor model of personality. J Adolesc. 23(4):393-407

Goldberg, L. R. (1981a). Language and individual differences: The search for universals in personality lexicons. In $\mathrm{L}$. Wheeler (Ed.), Review of personality and social psychology (Vol. 2, pp. 141-165). Beverly Hills, CA: Sage

Gullone E, Moore S (1996). Predicting adolescent risk behavior using a personalized costbenefit analysis. Journal of Youth and Adolescence, 25, 343-359

Hinze, J.W. (2006). Construction Safety. 2nd edn. Prentice Hall Inc.: New Jersey

Howell, G. A., G. Ballard, T. S. Abdelhamid, and P. Mitropoulos. (2002)." Working Near the Edge: a New Approach to Construction Safety." In ANNUAL CONFERENCE ON LEAN CONSTRUCTION, 10:49-60.

Hoyle, R. H., Feifar, M. C., \& Miller, J. D. (2000). Personality and sexual risk taking: A quantitative review. Journal of Personality, 68, 1203-1231

John, O.P., Srivastava, S. (1999). The Big Five Trait Taxonomy: History, measurement, and thereotical perspectives. New York: Guilford

Lawson, M. (2012). The psychology of Risk. Tms Consulting (2012)

Lazarus, R.S. (1976). Paterns of Adjustment. Tokyo: McGraw Hill Kogakusha,Ltd

Liebert, R.M., Poulos, R.W., \& Marmor, G.S. (1977). Developmental psychology (2 ${ }^{\text {nd }}$ ed). Englewood cliffs, N.J.: Prentice-Hall. low trait or state self-control increases social norm violations. Scientific Research, 1074-1083.

Liputan, 6. (2013, 1 13). Tower crane apartemen ambruk di ciputat 3 pekerja tewas. Retrieved $07 \quad 08, \quad 2017, \quad$ from http://news.liputan6.com/read/486581/tower-crane-apartemen-diciputat-ambruk-3-pekerja-tewas

Little, P., \& Zuckerman, M. (1986). Sensation seeking and music preferences. Personality and Individual Differences, 7, 575-577

Perkins, H. W. (2002b). Surveying the damage: A review of research on consequences of alcohol misuse in college populations. Journal of Studies on Alcohol, 14(Supplement), 91-100

Mischel, W., Shoda, Y., \& Smith, R. E. (2003). Personality, 7e. NY: Wiley.

McCrae R R., John O P. (1992). An Introduction to the Five-Factor Model and Its Applications. Volume 60, Issue 2 175-215 
McCrae, R.R \& Costa, P.T. (2003) Personality in adulthood (2nd eds.), New York, NY: The Guild for dpress.

McGhee, R. L., Ehrler, D. J., Buckhalt, J. A., Carol Philips (2012). The Relation between Five-Factor Personality Traits and Risk-Taking Behavior in Preadolescents. Journal of psychology, vol 3, 558-561

McMullen, John C. (1999). A Test of self-control theory using general pattern of deviance. Disertation of virginia polytechnic institute

Mecca, D. N. (2003). The relationship between pathological gambling and the Big-Five personality factors. Unpublished master's thesis, New Britain, CT: Central Connecticut State University

McAdams, D. P. (1992). The five-factor model in personality: A critical appraisal. Journal of Personality, 60, 329-361.

Nicholson, N., Soane, E., Fenton-O'Creevy, M., \& Willman, P. (2005). Personality and domain-specific risk taking. Journal of Risk Research, 8(2), 157-176

Perkins, H. W. (2002b). Surveying the damage: A review of research on consequences of alcohol misuse in college populations. Journal of Studies on Alcohol, 14(Supplement), 91-100. Retrieved from http://www.collegedrinkingprevention.gov/media/Journal/091_139.pd

Pervin, Cervone, John. (2005). Personality Theory and Research. 9 th Ed. New york : John Willey \& Sons, Inc

Pratama, P.M. (2015, 10 1). Begini kondisi korban crane roboh di kampung pulo. Retrieved $07 \quad 08, \quad 2017, \quad$ from http://news.liputan6.com/read/2330522/begini-kondisi-korban-craneroboh-di-kampung-pulo

Pribolšan, Marina. (2013). Association between personality traits, risk-taking on a behavioural task and risky behaviours. Diploma Thesis. Filozofski fakultet $\mathrm{u}$ Zagrebu, Department of Psychology

Purba, D.O. (2016, 10 26). Gondola yang jatuh di intiland tower belum digunakan sepenuhnya. Retrieved $07 \quad 08, \quad 2017$, from http://megapolitan.kompas.com/read/2016/10/26/13160261/gondola. yang.jatuh.di.intiland.tower.belum.pernah.digunakan.sebelumnya

Rurit, B. (2011, 11 27). Kisah ambruknya jembatan kutai kartanegara. Retrieved 07 08, 2017, from https://nasional.tempo.co/read/368626/kisah-korbanambruknya-jembatan-kutai

Shimmin, S., Corbett, J. and McHugh D. (1980) Human Behavior: Some Aspects of Risk-taking in the Construction Industry. Institute of Civil Engineering, London

Sutrisno, D. (2015, 9 10). Hanggar bandar makassar runtuh pejabat kemenhub diperiksa. Retrieved $07 \quad 08, \quad 2017, \quad$ from http://nasional.republika.co.id/berita/nasional/daerah/15/09/20/nuyp 8h335-hanggar-bandara-makassar-runtuh-pejabat-kemenhub-diperiksa

Tangney JP, Baumeister RF, Boone AL. (2004) High self-control predicts good adjustment, less pathology, better grades, and interpersonal success. J Pers.;72(2):271-324

Trimpop, R.M. (1994). The Psychology of Risk Taking Behavior, Handbook of advances in psychology (pp. 107). New York: Elsevier 
Umar, J. (2013). Logika CFA: Basic Concept. Bahan Ajar Perkuliahan Statistik 3. Tidak dipublikasikan. Fakultas Psikologi Universitas Islam Negeri Syarif Hidayatullah Jakarta

Vroom, V. H., \& Pahl, B. (1971). Relationship between age and risk taking among managers. Journal of applied psychology, 1971, 55, 5 399-405.

Vollrath, M., Torgersen, S. (2002). Who takes health risks? A probe into eight personality types. Personality and Individual Differences, Vol 32(7), 11851197.

Wallach, M. A., \& Kogan, N. Aspects of judgment and decision making: Interrelationships and changes with age. Behavioral Science, 1961, 6, 23-36.

Weber, E. U., Blais, A. R., Betz, N. E. (2002). A domain-specific risk attitude scale: measuring risk perceptions and risk behaviour. Journal of Behavioural Decision Making 15(2002) 263-290

Yates, J. (1992). Risk-Taking Behavior. Hoboken, NJ: John Wiley \& Sons

Zuckerman M., Kuhlman D. M., Thornquist M., Kiers H. (1991). Five (or three) robust questionnaire scale factors of personality without culture. Personality and Individual Differences, 12, 929-941 
